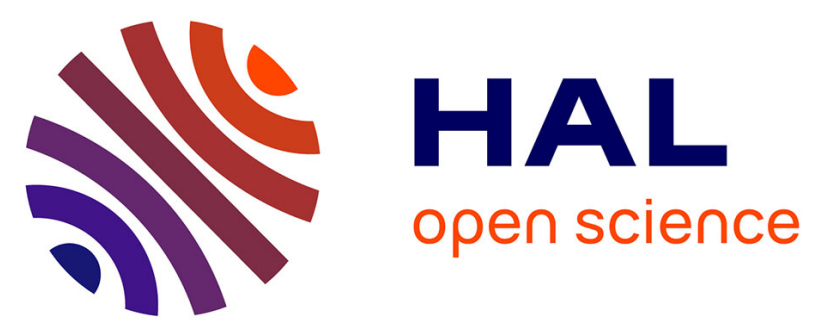

\title{
Are there variations in adherence to colorectal cancer clinical guidelines depending on treatment place and recommendation novelty? The French EvaCCoR observational study
}

S. Lamy, R. Guimbaud, L. Digue, I. Cirilo-Cassaigne, V. Bousser, E. Oum-Sack, J. Goddard, E. Bauvin, C. Delpierre, P. Grosclaude

\section{To cite this version:}

S. Lamy, R. Guimbaud, L. Digue, I. Cirilo-Cassaigne, V. Bousser, et al.. Are there variations in adherence to colorectal cancer clinical guidelines depending on treatment place and recommendation novelty? The French EvaCCoR observational study. Clinics and Research in Hepatology and Gastroenterology, 2019, 43, pp.346 - 356. 10.1016/j.clinre.2018.10.008 . hal-03486294

\author{
HAL Id: hal-03486294 \\ https://hal.science/hal-03486294
}

Submitted on 20 Dec 2021

HAL is a multi-disciplinary open access archive for the deposit and dissemination of scientific research documents, whether they are published or not. The documents may come from teaching and research institutions in France or abroad, or from public or private research centers.
L'archive ouverte pluridisciplinaire HAL, est destinée au dépôt et à la diffusion de documents scientifiques de niveau recherche, publiés ou non, émanant des établissements d'enseignement et de recherche français ou étrangers, des laboratoires publics ou privés.

\section{(ㅇ)(1) $\$$}

Distributed under a Creative Commons Attribution - NonCommerciall 4.0 International 
Are there variations in adherence to colorectal cancer clinical guidelines depending on treatment place and recommendation novelty? The French EvaCCoR observational study.

\section{Recommendation novelty, place of treatment and difference in CRC guidelines adherence}

\section{AUTHORS:}

Lamy $\mathrm{S}^{1,2,3}$; Guimbaud R $\mathrm{R}^{4,5}$; Digue L D ${ }^{67}$, Cirilo-Cassaigne $\mathrm{I}^{6}$; Bousser V B ; Oum-Sack $\mathrm{E}^{5}$; Goddard J5, Bauvin $\mathrm{E}^{5}$; Delpierre $\mathrm{C}^{3} ; \mathrm{P}$. Grosclaude ${ }^{3,8}$ and the EvaCCoR Group

AFFILIATION: 1 - University of Toulouse III Paul Sabatier, Toulouse, France; 2 - Department of Clinical Pharmacology, Toulouse University Hospital, Toulouse, France; 3 - INSERM UMR1027 (The French National Institute of Health and Medical Research), Toulouse, France; 4 - Digestive medical oncology unit, Toulouse University Hospital, Toulouse University Cancer Institute (IUCT-O), Toulouse, France; 5 - Occitanie Regional cancer network (Onco-Occitanie), Toulouse, France; 6 - Aquitaine regional cancer network, Bordeaux, France; 7Department of clinical oncology, Bordeaux University Hospital, Bordeaux, France; 8 - Tarn Cancers Registry, Albi, France;

\section{CORRESPONDING AUTHOR:}

Dr Sébastien Lamy,

UMR Université de Toulouse Paul Sabatier - Inserm 1027 ; Equipe labelisée LIGUE Contre le cancer Faculté de Médecine, UMR 1027 Inserm, 37 allées Jules Guesde, 31062 Toulouse, FRANCE phone: +33561145648; fax: +33562264240; email: sebastien.lamy@univ-tlse3.fr / sebastien.lamy@inserm.fr

Acknowledgements: Members of the EVACCOR working group : Claude ALZIEU; Eric BARANDON; Eric BAUVIN; Yves BECOUARN; Geneviève BELLEANNEE; Daniel BERCOVICl; Laurent BERTHOUX; Jean-Frédéric BLANC; Annie BOISSEAU; Nathalie BONICHON-LAMICHHANE; Véronique BOUSSER; Eric BRUDIEUX; Anne-Laure CAZEAU; Thierry CHAUBARD; Christian CHEVELLE; Pascal CHEVREAU; Jean-Marc COMBIS; Cyrille DELPIERRE; Laurence DIGUE; Michel ESCARTIN; Serge EVRARD; Marianne FONCK; Bertrand FOPPA; MarieHélène GASPARD; Jérôme GODDARD; Karine GORDIEN; Pascale GROSCLAUDE; Rosine GUIMBAUD; Françoise IZAR; Dominique JAUBERT; Marce Amara KPOGHOMOU; Sébastien LAMY; Hervé LAUMONIER; Christophe LAURENT; Cédric LECAILLE; Robin LECESNE; Alain LEDIT; Eric MAGNE; Patrice MAHE; Simone MATHOULIN-PELISSIER; Philippe OTAL; Edvie OUM SACK; Françoise PERRAUDEAU; Guillaume PORTIER; Joëlle REYRE; Pierre RICHAUD; Isabelle ROQUE; Dominique ROUX; Karine SALIGNON; Janick SELVES; Denis SMITH; Isabelle SOUBEYRAN; Bruno TRAVERS; Jean TROCARD; Véronique VEN

Availability of data and materials: Data are available upon request. Please, contact the EvaCCor project coordinators: bauvin@onco-occitanie.fr; pascale.grosclaude@inserm.fr

Conflict of interest: The authors declare no conflict of interest

Funding: Data collection was funding by the French National Cancer Institute: grant number 2010-380. The analyses were funded by both the French Direction générale de la santé (the National General Directorate of Health), the French Caisse nationale d'assurance maladie des travailleurs salariés (the national health care insurance services for the employees), the Inserm (the National Institute for Health and Medical research), and the national cancer plan through the grant AAP IResP-2015_08. The authors also thank the French National Research Agency for funding the work of LS (grant "Investissement d'Avenir" ANR-11-PHUC-001).

Authorship: LS, CD, PG, GR, DL, BV and BE designed research; CCI, OSE, and GJ collected and controlled the data; LS, DL, BV, DC, and GP analysed the data; LS, GR, DL, DC, and GP discussed the results and wrote the paper. All authors reviewed, commented, and approved the manuscript. 


\begin{abstract}
Background: Studies have shown clinical practices variation between centers in colorectal cancer (CRC) management. After the implementation of national cancer plans, we tested for differences in center and patients' socioeconomic position (SEP)-related variation in CRC guidelines. Methods: All patients aged 18 years and over, cared for a first CRC in 2010 in Southwest of France. We used mixed effect model to test for center-related heterogeneity $(\mathrm{CRH})$ in recommendation, from the oldest to the more recent: 1/ at least 12 lymph nodes analysed for stage II, 2 / the prescription of adjuvant chemotherapy stage III and $3 /$ the assessment of CRC molecular phenotype regarding KRAS status for stage IV. Patients' SEP was approached by an ecological social deprivation index. Results: We found: higher adherence for the oldest than for the most recent recommendations; no $\mathrm{CRH}$ in recommendation $n^{\circ} 2$ but lower adherence in academic centers; a CRH for recommendations $n^{\circ} 1$ and 3 ; no SEPrelated differences in clinical practices. Conclusion: Results showed that older recommendations have higher adherence but did not support increasing influence of centers characteristics and $\mathrm{CRH}$ as recommendations are more recent.
\end{abstract}

\title{
KEYWORDS:
}

adherence to guidelines; between-center variation; observational study; colorectal cancer management; social inequality in health 


\section{INTRODUCTION}

Colorectal cancer (CRC) is one of the most common cancers and causes of death from cancer as well in France (1) as in the rest of Europe where the International Agency for Research on Cancer estimated 447,000 new cases and 215,000 deaths from cancer attributable to CRC (2). However recent data from the EUROCARE group show disparities in CRC overall survival between European countries (3). These observations may reflect differences in patterns of care (4) which may be explained, at least partially, by discrepancies in wealth and health-care organisation across Europe (5). For instance, Dejardin et al. showed that, contrarily to what was observed in France, the distance to health services alone did not influence relative survival of CRC patients in United-Kingdom (6). However, differences in CRC management are not confined to inter-country level and were also observed within countries with different healthcare systems organisation, e.g. in the USA (7)., the Netherlands (8) or in France (9)..

In France, indeed inthe early 80s, Launoy et al. showed disparities across centers in the utilization of adjuvant radiotherapy for rectal cancer patients (9). The same was pointed out regarding the diffusion of care standards in the 1990-1999 period during which registry data showed that consensus guidelines are disseminated more rapidly in university or comprehensive cancer centers. In this same time lapse, the proportion of patients treated outside the university hospitals or comprehensive cancer centers declined from almost $40 \%$ in 1990 to less than $30 \%$ in 1999. Concomitantly, the proportion of patients treated in private centers increased to become predominant, with a trend toward less advanced tumours (10). Regional variations in CRC management were supported by population registry-based studies showing, for instance, that in the early 2000s rectal cancer management practices varied across regions for colonoscopy, preoperative assessment, adjuvant treatment but not for resection, colostomy and staging (11). Similar patterns were observed regarding colon cancer with strong regional variations of management practices found for staging and adjuvant chemotherapy among stage II patients (12). However throughout this period efforts were done for standardizing CRC management, notably with the holding of consensus conferences in Paris for rectum cancer first $(13)$, and then for colon cancer $(14,15)$. This was reinforced by the implementation of the national cancer plans which aimed, at developing cancer coordination centers responsible of the holding of multidisciplinary team meeting (MTM) for the first plan (20032007 ) and the reduction of social and territorial inequalities in cancer management for the second and third plans (2009-2013/2014-2019). Moreover, since 2009, centers must officially obtain the authorization to manage cancer patients. The accreditation standard includes notably a minimal level of activity for some specific treatments or cancer types. From healthcare organisation point of view, the healthcare organisation is centralised and relayed at the regional level by Regional Health Agency. Patients' cancer management can be carried out by public Teaching hospital or comprehensive cancer centers (non-profit private center), private or public hospitals not affiliated to a university, all funded by the National Health Insurance according to their activity. All these centers shared the same mission of treating and caring for patients. Patients are free to choose the place wherein they will be treated.

The objective of our study was to examine whether and why adherence to guidelines differs between care centers. We tested for variations in adherence to guidelines between centers and investigated if they were explained by differences in the characteristics of the patients, the geographical region, or the centers' characteristics. This approach was applied to three recommendations from international guidelines (16-19): the analysis of at least 12 lymph nodes to avoid under-staging, i.e. false N0, among stage II (T3-4NOMO) patients; the prescription of adjuvant chemotherapy among stage III (N1-2M0) patients; and the assessment of molecular phenotype of colorectal tumours regarding KRAS status within 6 months after diagnosis among stage IV (M1) patients. These recommendations date respectively from the mid-1990s, the late 1990s / early 2000s, and the late 2000s / early 2010s. We tested for two hypotheses regarding the diffusion of adherence to guidelines over centers. First, we assume older recommendations may be more largely diffused in the centers over the whole territory than the more recent. In other words, we assume that older recommendations have higher adherence and lower center-effect. Second, as a potential explicative mechanism, we assume therapeutic progresses among which we include guideline-based practices - diffuse first in university hospitals or comprehensive cancer centers before to extend to peripheral, less specialised, centers $(9,10)$.

\section{Material and methods}




\section{Study design and population}

Data came from the EvaCCoR longitudinal retrospective observational study, which aimed at evaluating the quality of the initial management of colorectal cancer patients developed in two French regional and neighbouring cancer networks, in Aquitaine and in Midi-Pyrénées regions representing a total of more than 6 million inhabitants. In each region, cancer coordination centers regrouping one or several cancer care centers ensure, amongst others, the smooth running of MTM, wherein patients' management are discussed based on clinical guidelines and patients' characteristics. The therapeutic decisions for each patient are recorded and made available for the clinicians in a computerized shared-file, the DCC (dossier communicant de cancérologie). From the MTM records, all patients aged 18 years and over, with a first diagnosis of CRC between the $1^{\text {st }}$ January 2010 and the 31st December 2010, discussed in MTM, and cared for in both regions were eligible for inclusion. We included colorectal adenocarcinoma histologically confirmed from information available in medical records Exclusion criteria encompassed being presented in MTM for a relapse or for post-treatment monitoring and being cared for outside the regions of interest. The EvaCCoR sample was constituted by including one on two eligible patients on each region resulting in 2074 patients (1079 patients in the Midi-Pyrénées and 995 in Aquitaine). Both regions have been anonymised in the rest of this paper, as region $A$ or $B$, randomly.

The present study dealt with the diffusion of innovation in CRC management practices. From the oldest to the most recent, we studied the number of lymph nodes analysed (at least 12 or less) among patient with stage II (T3-4NOM0), the use of adjuvant chemotherapy (presence or absence) among patients with stage III (N1-2M0), the assessment of molecular phenotype of the tumours regarding KRAS status (presence or absence of a request for KRAS mutation testing) among patients with stage IV (M1). Cancer stage was defined using the $7^{\text {th }}$ revision of the TNM classification (20).

\section{Data collection}

A reading grid was developed for the EvaCCoR study to collect data from patients' medical records or through the DCC including different sections: patients' general information; cancer location;circumstance of hospital admission; places where patients were cared for; past medical history and comorbidities; diagnosis, pretherapeutic and extension assessments; histological assessment of anatomic piece; surgery and other treatments; molecular profiles assessment; MTM report and proposals; and treatment received

\section{Clinical recommendations under study}

We chose to test disparities between centers according to three recommendations from international guidelines (16-19). We focused on (Analysis 1) the number of lymph nodes analysed (at least 12 or less to avoid understaging, i.e. false N0) among patients with stage II (T3-4NOM0); (Analysis 2) the use of adjuvant chemotherapy (presence or absence) among patients with stage III (N1-2M0); and (Analysis 3) the assessment of molecular phenotype of colorectal tumours regarding KRAS status within 6 months after diagnosis among stage IV (M1) patients. Indeed, we assume these elements to correspond, at the time of the study, respectively to two old and largely adopted recommendations and one more recent recommendation rooted in the targeted therapy area. Adherence to recommendation was assessed from the medical records regarding information on what was actually done.

\section{Care centers and centers characteristics}

We assume that the centers influence on adherence to guidelines result from two components: the center-effect and the effect of centers characteristics. The first reflects the between-centers differences (i.e. heterogeneity) in adherence to guidelines associated with the place of care. The overall variation in the proportion of adherence to guidelines between centers without accounting for differences in recruited patients' profiles or centers characteristics corresponds to crude center effect. Thus, the center effect estimated after adjustment for patients' and centers' characteristics corresponds to the adjusted center effect which documents the unexplained betweencenters variation in the outcome. The second reflects the influence of centers characteristics, including its geographical location, seen as exposure linked to the care environment wherein patients are treated. The care center was identified for each patient. We defined the care center as the place where patients underwent surgery or if not, where they underwent biopsy. We considered the place of surgery/biopsy rather than the place of MTM, chemotherapy, or radiotherapy, because surgery represents a key-step in the management of colorectal cancer. Indeed, the information obtained from the biopsy and the resected tissue, as well as its quality, influence staging and the therapeutic decision. Centers characteristics encompassed the center geographical location (region A or B) and the type of the care facility where the patients were treated. Public Teaching hospital or private 
comprehensive cancer centers were grouped under the denomination "academic center" ( 5 centers), private or public hospitals not affiliated to a university were respectively named "private non-academic center" (48 centers) and "public non-academic center" (29 centres).

\section{Patients' characteristics}

We used patients' age, gender, cancer location (colon or rectum), comorbidity (none, at least one), pTNM stage at diagnosis (T1-T2NOM0; T3-T4NOM0; N1-2M0; M1), circumstance of hospital admission (elective or emergency) and the treatment proposed by the MTM. As socioeconomic information is not collected in routine in medical files, the patients' place of residence was used to attribute to each patient the socioeconomic position of his residence area. We used the French version of the European ecological deprivation index (EDI) aggregated at the infra-communal level: the 'llots regroupés d'information statistiques' (IRIS) corresponding to an average of 2000 inhabitant, the smallest level for socioeconomic information in France. Similarly to what was done to study social inequalities in cancer care elsewhere (21), we used EDI score as a proxy of individual socioeconomic status (22). Indeed, we assumed that, in average, differences in socioeconomic status between people of the same IRIS are smaller than between from different IRIS. Evidence exists suggesting that this assumption is reasonable (23). These data allowed us to adjust our analyses for the potential between-centers-differences in the recruitment of patients.

\section{Data analysis}

Adherence to recommendations was treated as binary variable (adherence versus non-adherence). We used multilevel logistic model, i.e. generalized linear models with random intercept, to allow the probability of adherence to recommendation to vary between the care centers (level 2) and between patients within centers (level 1). From the level-1 and level-2 variances, we estimate the infraclass correlation coefficient (ICC) to assess the contribution of the between-centers variance in the whole variance of the response variable. In other words the ICC allows to estimate the fraction of the differences in adherence to guidelines attributable to the center effect, i.e. to the differences between centers (24). Consequently, all the models included two components: $1 /$ the fixed effects corresponding to the effect of covariates on outcome translated in odds ratios, and $2 /$ the random effects corresponding to the level-1 and level-2 variances of the outcome.For each recommendation we constructed an empty model to assess the crude center effect. This represents the fraction of the total variation in adherence to guidelines attributable to difference between centres before adjusting for potential explicative factors. These models were progressively adjusted for level- 1 and level-2 variables to test for compositional and contextual effect (25): empty models were additionally adjusted for patients' characteristics to control for potential difference in centers recruitment, and then for region and the care facility type to control for potential difference in centres characteristics. Our models included all variables associated with these outcomes in bivariate analyses at the threshold of 0.2 . The models were systematically adjusted for age, sex, comorbidity and socioeconomic status. All analyses were done by using STATA release 14 (StataCorp LP, College Station, TX, USA).

\section{RESULTS}

In this study, we analysed 458 stage II (T3-4NOM0) patients (analysis 1), 397 stage III (N1-2M0) patients (analysis 2), and 516 stage IV (M1) patients (analysis 3). The flowchart is presented in figure 1. Overall, between the eligible and analysed samples, we excluded about $6 \%$ of the sample due to missing data. However, no differences in age, sex, comorbidity, place of care, and socioeconomic position were found between not analysed and analysed patients (data not shown).

\section{(insert figure 1 about here)}

The details of samples characteristics are given in table 1. Globally, whatever the sample considered, the patients were more often in non-academic centers than in academic centers, and about $50 \%$ had no comorbidity. Overall, respectively $81 \%$ (373/458), $71 \%$ (281/397), and $68 \%$ (353/516) of patients were managed according to the clinical recommendations regarding respectively the number of lymph nodes to be analysed among stage II patients, the prescription of adjuvant chemotherapy among stage III patients, and the access to KRAS testing among stage IV patients. 
Table 1: Sample characteristics for each analysis

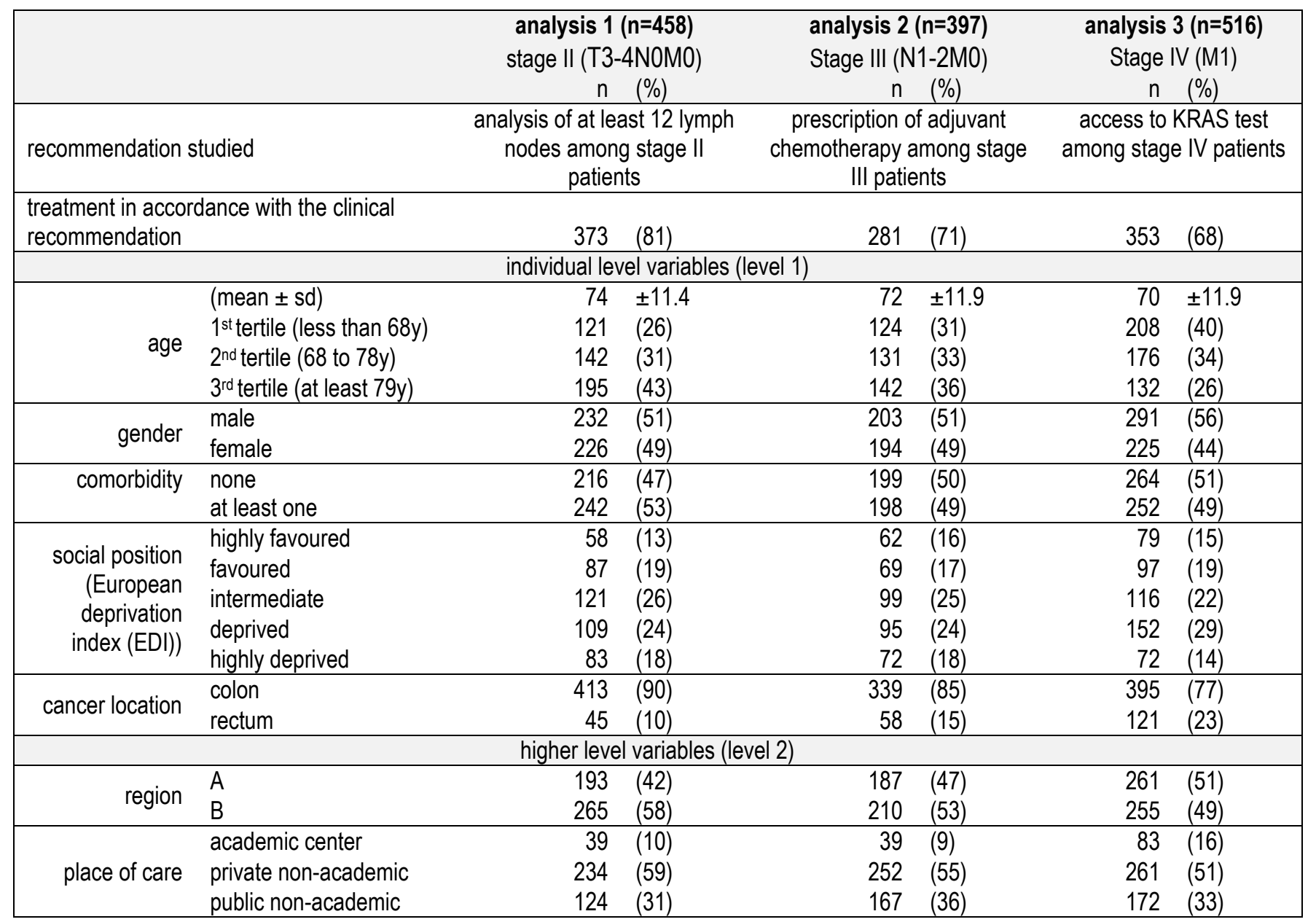

In response to our primary objective, table 2 presented the fraction of the total variation in adherence to guidelines attributable to the center effect, i.e. to between-centers crude differences in adherence to guidelines. These information correspond to the random component of the models for the analyses 1,2 and 3 . The fixed component of these models are presented respectively in tables 3,4 , and 5 .

In Table 2, for the analysis 1, results from the empty model, i.e. without adjustment for any potential explanatory factors, showed that almost one fifth $(19.5 \%[8.4 ; 38.8](\%[95 \% \mathrm{Cl}]))$ of the total variation in crude the proportion of adherence to the recommendation regarding the number of lymph nodes to analyse among stage II patients was attributable to differences between centers. This estimation remained stable after adjustment for patients' characteristics (level 1) and centers characteristics (level 2) in terms of academic affiliation and public/private funding and geographical location. The center effect observed here was therefore not explained by differences in the characteristics of the patients recruited or in center characteristics. The centre effect, that is the center-related heterogeneity in adherence guidelines, resisted to the adjustment for covariates and remained unexplained. For the analysis 2 , the results from the empty model showed a smaller crude center-effect. We estimated that $6.6 \%$ $[1.3 ; 28.1]$ of the total variation in the crude the proportion of adherence to the recommendation regarding the use of adjuvant chemotherapy among stage III patients was attributable to differences between centers. However, as shown in table 2, adjusting models for covariates reduced the centre effect to less than $0.1 \%$ suggesting that the differences in the crude the proportion of guidelines adherence for this recommendation were completely explained by differences in patients' characteristics within centers. For the analysis 3 , the empty model showed that $5.8 \%[1.4 ; 21.4]$ of the total variation in the crude the proportion of adherence to the recommendation regarding KRAS testing among stage IV patients was attributable to differences between centres. This fraction increased after adjustment for patients' characteristics within centers to $8.4 \%[2.1 ; 26.0]$. This estimation 
corresponds to the fraction of the total variation in the outcome attributable to the centre effect that are not explained by differences in patients' characteristics within centers. Lastly after adjusting this model for centers characteristics, this fraction halved $(3.9 \%[0.4 ; 29.2])$, that is about $4 \%$ of the total variation in the proportion of adherence to guidelines remained unexplained by differences in recruited patients' profile or centers characteristics.

Table 2: percentage of the total variation of the outcome probability explained by the center effect, i.e. between centers differences in the adherence to guidelines

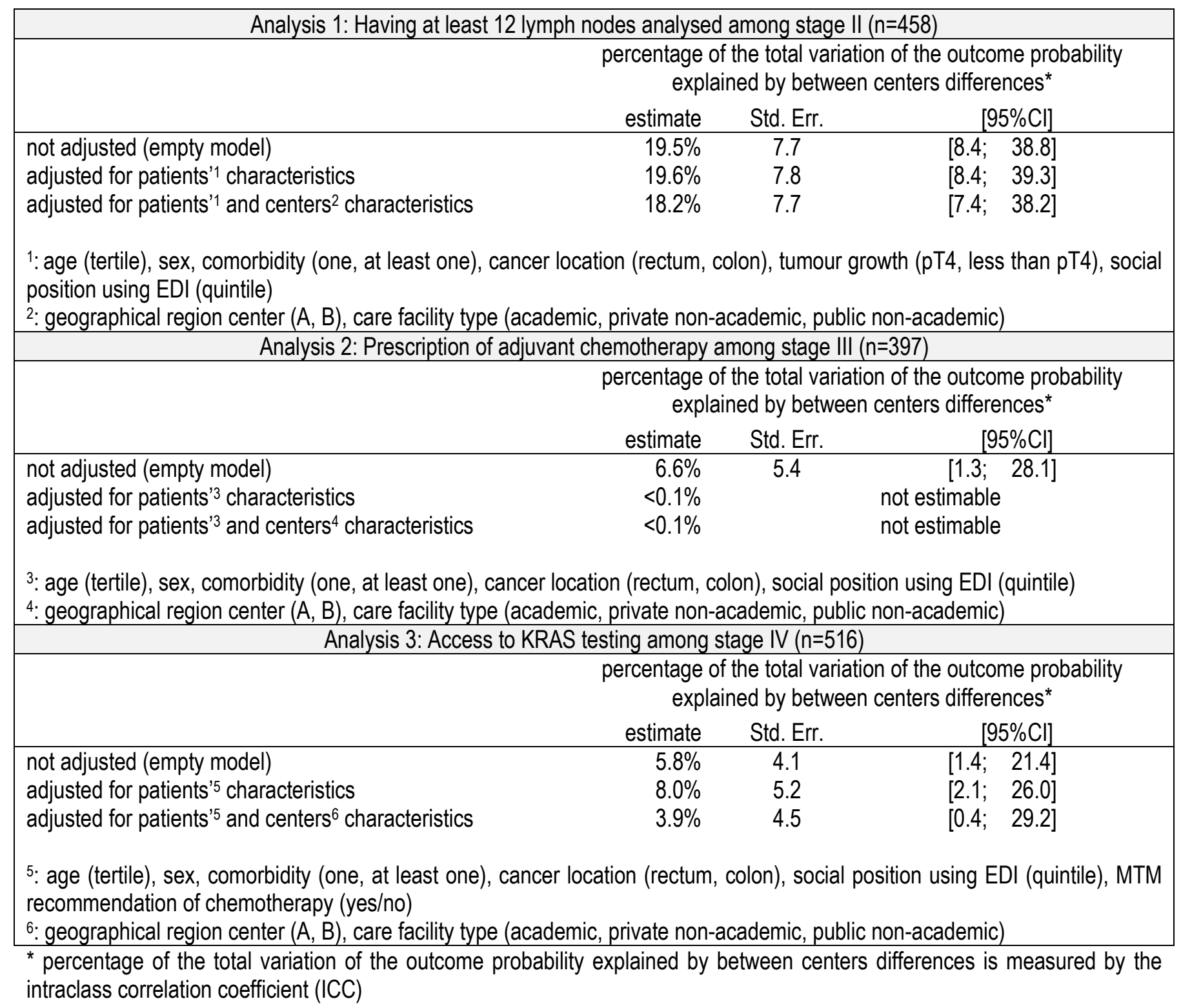

Results from tables 3,4 , and 5 showed the factors potentially explaining the centers-related variations in adherence to guidelines respectively in analyses 1,2 and 3. In table 3, advanced age was associated with a lower probability of having at least 12 lymph nodes analysed in the model only adjusted for the level-1 variables and this association persisted after additional adjustment for level-2 variables. In table 4, in the model only adjusted for the level-1 variables, advanced age was associated with a lower probability of adjuvant chemotherapy use. In the model additionally adjusted for level-2 variables, advanced age, the presence of comorbidities and being managed outside academic center were associated with a higher probability of adjuvant chemotherapy prescription. In table 5, in the model only adjusted for the level-1 variables, advanced age and 
comorbidity were associated with lower probability of KRAS testing. Conversely, the use of chemotherapy was very strongly associated with higher probability of KRAS testing. These associations persisted in the model additionally adjusted for level-2 variables. 


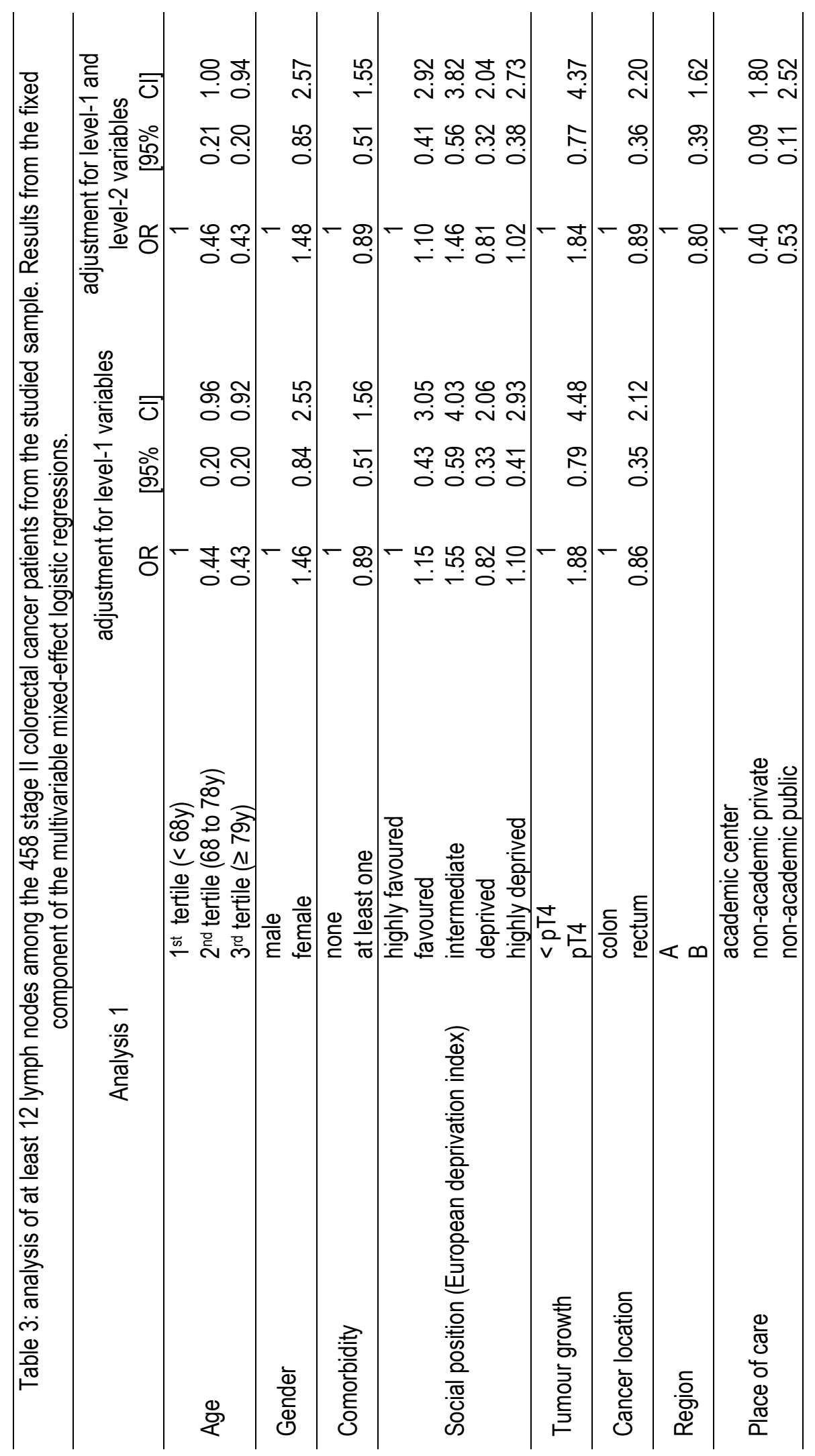




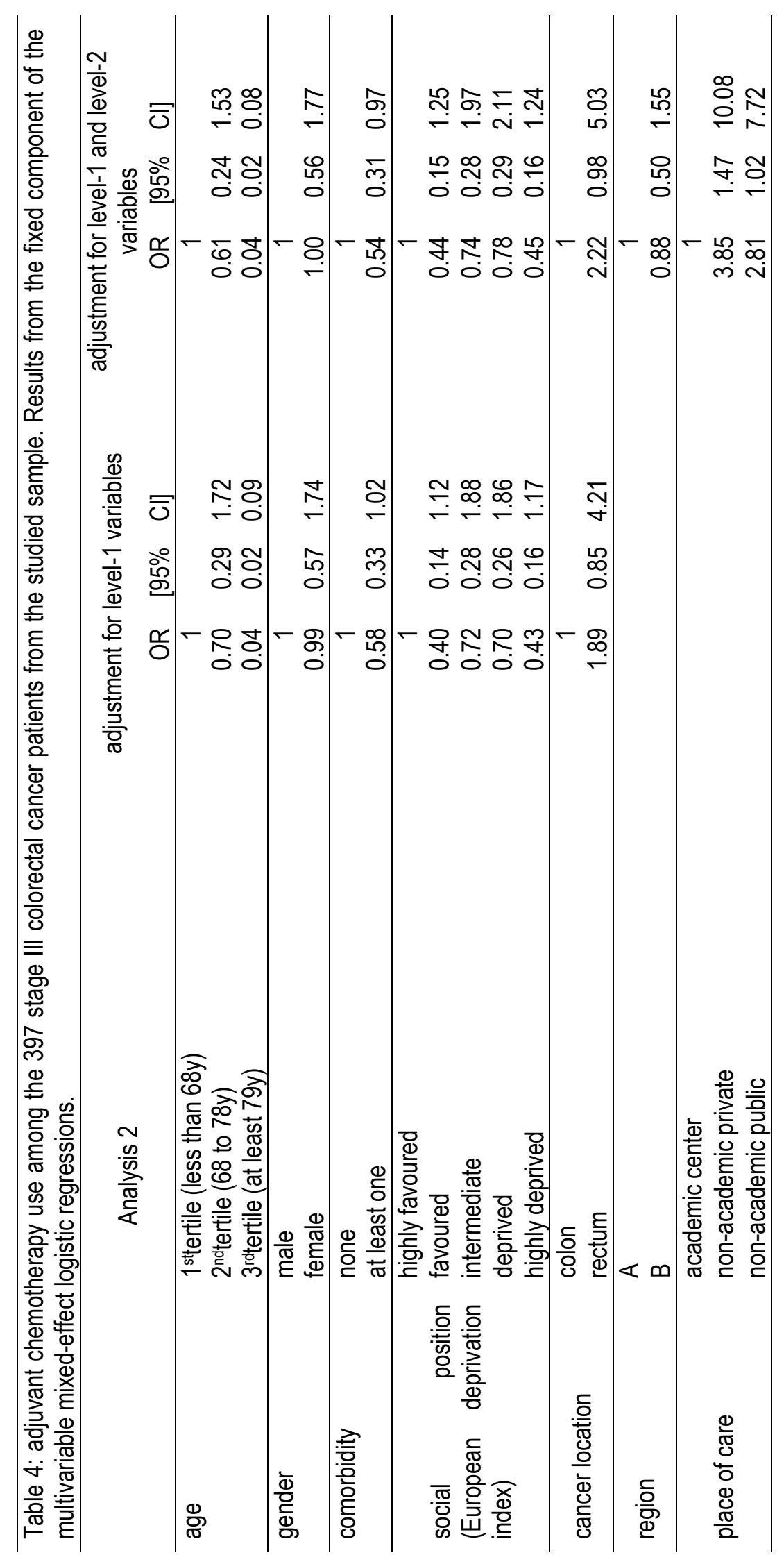




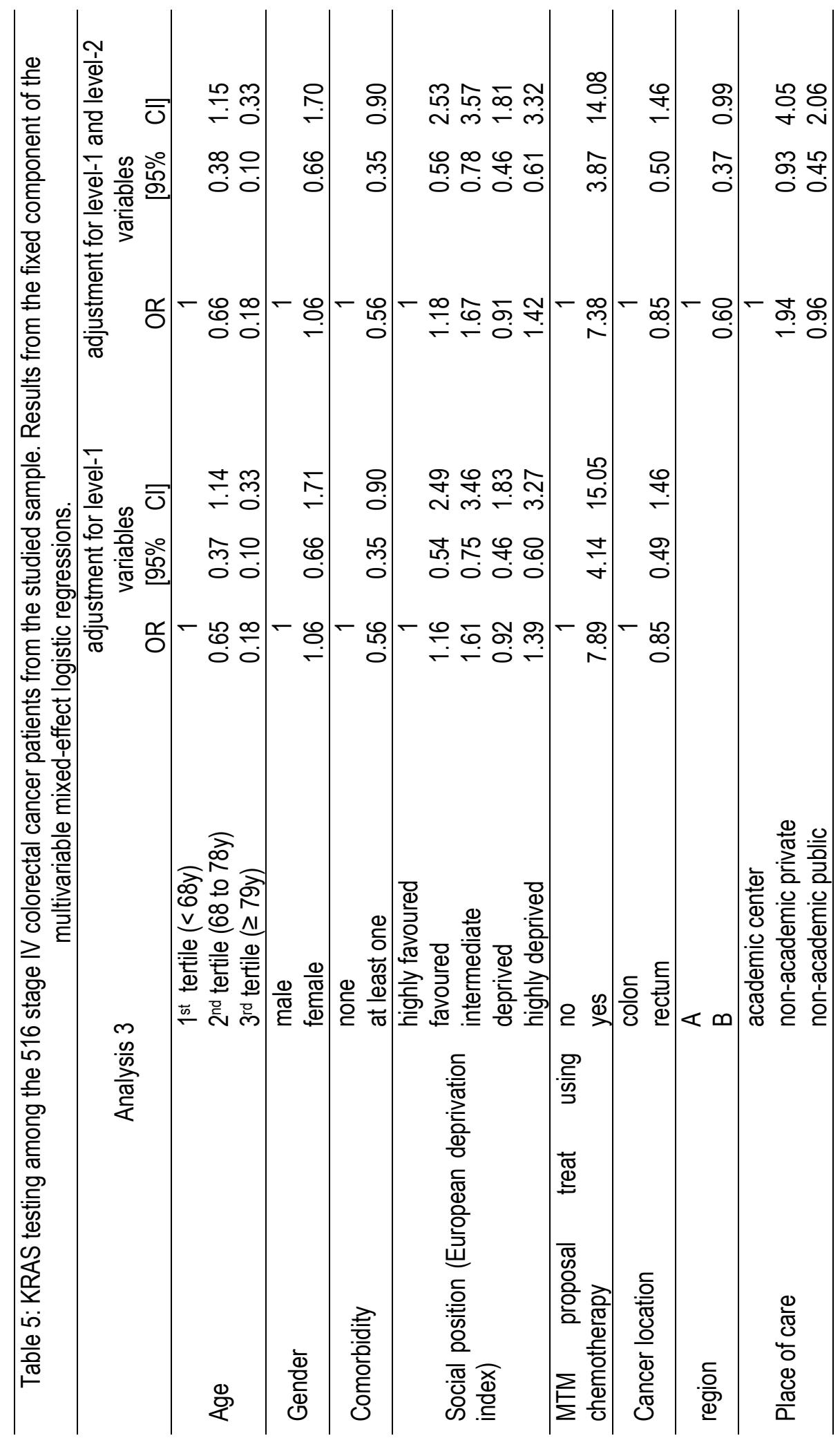




\section{DISCUSSION}

The present study dealt with the diffusion of guideline-based practices in colorectal cancer management in investigating whether and why adherence to guidelines varied between care centers. As expected, we found higher overall proportions of guideline-based practices for the former clinical recommendations than for the most recent. However, contrarily to our expectation, we did not find the largest center effects for the most recent recommendations. Lastly, results regarding the assumption of an academic-to-non-academic diffusion mechanism of guidelines adherence are unclear and seem to depend on the type of recommendation.

The EvaCCoR study was initially designed as a care quality evaluation with a concern of representativeness of the centers belonging to the regional cancer networks in Aquitaine and Midi-Pyrénées. This allowed us to draw a picture of the way patients with colorectal cancer diagnosed in 2010 were managed in both regions. Altogether in 2010 these regions counted about 6 million inhabitants representing about $10 \%$ of the overall French population. Moreover, it is unlikely that te healthcare organisation differed between the two regions as it is centralised and relayed at the regional level by Regional Health AgencyPatients included in the EvaCCoR study were diagnosed at different stages of their disease and we had information on their first year of treatment. Thus, we could study several steps of the colorectal cancer management from the same study sample, i.e. among people submitted to the same geographical, historical and organisational contexts. In this study we assessed the center-related variation in guideline-based clinical practices while accounting for patients' socioeconomic position obtained despite the absence of information about patients' socioeconomic position in their medical records, by using a validated ecological index of social deprivation from their address of residence as a proxy of the individual situation. The use of the smallest geographical unit available including the patients' place of residence reduced the risk of ecological fallacy. However, our work had some limitations. The first main one relied on the fact that data were collected from the medical files and were thus dependent of the quality of these documents. Otherwise, the absence of any information concerning an act of care could mean either that this act was not done, or that it was done but not reported in the medical files. However, this issue concerned only a small proportion of our samples, as data missed among only $5 \%$ of stage III patients, and $7 \%$ of stages II and IV patients. No differences in age, sex, comorbidities, place of care, and socioeconomic position were found between analysed and not analysed patients. The second main limit is that patients were identified by the discussion of their management plan in the MTM, which means that we focused on patients who had already passed the first barrier of access to care. In other words, we may have lost in representativeness as evidences in the same geographical region supported a lower propensity to be discussed in the MTM among the oldest patients while the elaboration of an adequate management plan is more likely to be complex among these patients $(26,27)$. This may have led to overestimation of the rate of guideline-based practices. Finally, at the time of the study we had no data regarding patients' survival. Therefore, if we can study center-related disparity in adherence to guideline-based clinical practices, we cannot extrapolate our observations in terms of clinical benefit in terms of survival. This will be done in a further project as soon as 5 year-follow up data will be available.

Our results showed that four in five stage II patients have at least 12 lymph nodes analysed. The adhesion to this recommendation increased in France where regional cancer registry data (Calvados) gave estimation from $32 \%$ in 1997 to $55 \%$ in 2004 (28). Our estimation of about $81 \%$ of adhesion in 2010 seems to confirm this tendency. However, despite this recommendation is well followed, we found a strong center-effect that was neither explained by patients' nor centers characteristics. In the 2000s, data suggest that lymph node evaluation may be influenced by the hospital academic affiliation (29) and volume of surgical activity (28), but also the surgeon and pathologist experience (30). Indeed, the number of lymph nodes to analyse is conditioned by the quality and quantity of the resected tissue (31). Thus, such factors, that were not assessed in our study, may have had strong geographical variability and participate to the between-center disparities we failed to explain. Moreover, the contradictory results found in the literature regarding the impact of the analysis of a sufficient number of lymph nodes on patients' survival (32-35), as well as how is define "sufficient" (12 according to UICC and AJCC (36) versus 8 according to the French consensus conference), may have not facilitate the homogeneous diffusion of this practice (37). 
The use of adjuvant chemotherapy among stage III patients concerned 7 in 10 patients in our study. Given the observation made on 1995 and 2000 data from population-based registries $(12,38)$, among patients up to 75 years, our estimation is in the high portion of what was previously observed. Moreover, when consider only stage III patients up to 75 years we found higher rates (92\%) which may suggest an improvement in the guidelines adherence. However, this must be tempered as previous data came from population-based registries whereas ours are based on patients discussed in MTM. This would have led us to overestimation as evidences exist in the same geographical area supporting a lower propensity to be discussed in the MTM among the oldest patients $(26,27)$ and many studies in cancer supported age to be associated with lower access to curative treatment $(39$, 40). Our results showed that differences in patients' characteristics between centers were sufficient to explain the crude moderate center-effect we initially observed. Moreover, we observed a lower adherence in academic than in non-academic centers although this recommendation is old and relatively well accepted. This may translate the emergence of a potential new care standard. In that sense, this last observation may support the assumption of a diffusion of therapeutic innovation, including clinical recommendations, from academic to non-academic centres. But this calls for further investigations.

Regarding stage IV patients' management, we estimated that about two on three patients had a request for KRAS testing which was lower than the previous observation of more than $80 \%$ in 2010 in a multicentric study on physician practice (41). Although the consideration of tumour molecular features was introduced relatively recently in the therapeutic decision, recent evidences supported that KRAS testing is part of the management of most of patients with a metastatic colorectal cancer in France, despite discrepancies observed in the rate of prescription (42). In our study, we found a moderate center-effect reflecting, at least in part, the influence of the geographical region where centers were located but not of the care facility type. This did not support our initial assumption of diffusion of guideline-based practices, from academic or comprehensive centers to peripheral and less specialised centers.

\section{Conclusion}

Finally, our results support the assumption of better adherence to older recommendations which may translate that guidelines times to be adopted. However, despite the efforts done for standardizing CRC management, substantial differences in practice persisted between centers. Contrarily to our expectation, higher average adherence to older recommendations was not associated with lower unexplained center effect. As well, for the more recent recommendations, findings are more equivocal regarding the assumption of academic-to-nonacademic diffusion mechanism of adherence to guidelines. These suggest that mechanisms explaining the between-centers differences in adherence to guidelines may be multiple, variable and dependent on the nature of the recommendation. This illustrates the complexity of assessing clinical practices using real life data. Further study may investigate whether unexplained between-centers differences in adherence to guidelines leads to survival disparities.

\section{ADDITIONAL INFORMATION}

Ethics approval and consent to participate: The EVACCOR project was approved by national ethics committee (Comité Consultatif sur le Traitement de l'Information en matière de Recherche dans le domaine de la Santé), and declared to the Commission Nationale de l'Informatique et des Libertés ( $N^{\circ}$ 911233). 


\section{REFERENCES}

1. Binder-Foucard F, Bossard N, Delafosse P, Belot A, Woronoff AS, Remontet L. Cancer incidence and mortality in France over the 1980-2012 period: Solid tumors. Revue d'Épidémiologie et de Santé Publique. 2014;62(2):95-108.

2. Ferlay J, Steliarova-Foucher E, Lortet-Tieulent J, Rosso S, Coebergh JWW, Comber H, et al. Cancer incidence and mortality patterns in Europe: Estimates for 40 countries in 2012. European Journal of Cancer. 2013;49(6):1374-403.

3. De Angelis R, Sant M, Coleman MP, Francisci S, Baili P, Pierannunzio D, et al. Cancer survival in Europe 1999-2007 by country and age: results of EUROCARE-5-a population-based study. The Lancet Oncology. 2014;15(1):23-34.

4. Gatta G, Zigon G, Aareleid T, Ardanaz E, Bielska-Lasota M, Galceran J, et al. Patterns of care for European colorectal cancer patients diagnosed 1996-1998: a EUROCARE high resolution study. Acta Oncol. 2010;49(6):776-83.

5. Gatta G, Trama A, Capocaccia R. Variations in Cancer Survival and Patterns of Care Across Europe: Roles of Wealth and Health-Care Organization. JNCI Monographs. 2013;2013(46):79-87.

6. Dejardin O, Jones AP, Rachet B, Morris E, Bouvier V, Jooste V, et al. The influence of geographical access to health care and material deprivation on colorectal cancer survival: Evidence from France and England. Health Place. 2014;30:36-44.

7. Charlton ME, Hrabe JE, Wright KB, Schlichting JA, McDowell BD, Halfdanarson TR, et al. Hospital Characteristics Associated with Stage II/III Rectal Cancer Guideline Concordant Care: Analysis of Surveillance, Epidemiology and End Results-Medicare Data. Journal of Gastrointestinal Surgery. 2016;20(5):1002-11.

8. Heins MJ, de Jong JD, Spronk I, Ho VKY, Brink M, Korevaar JC. Adherence to cancer treatment guidelines: influence of general and cancer-specific guideline characteristics. European Journal of Public Health. 2017;27(4):616-20.

9. Launoy G, Soumrany A, Pottier D, Gignoux M. [Study of the diffusion of therapeutic progress in a morbidity register. Exemplified by rectal cancer in Calvados]. Rev Epidemiol Sante Publique. 1991;39(6):523-9.

10. Bouhier $K$, Maurel J, Lefevre H, Bouin M, Arsène D, Launoy G. Changing practices for diagnosis and treatment of colorectal cancer in calvados: 1990-1999. Gastroentérologie Clinique et Biologique. 2004;28(4):371-6.

11. Phelip JM, Launoy G, Colonna M, Grosclaude P, Velten M, Danzon A, et al. Regional variations in management of rectal cancer in France. Gastroenterol Clin Biol. 2004;28(4):378-83.

12. Phelip JM, Grosclaude P, Launoy G, Colonna M, Danzon A, Velten M, et al. Are there regional differences in the management of colon cancer in France? Eur J Cancer Prev. 2005;14(1):31-7.

13. Consensus conference, editor [Choice of treatment in rectal cancer. Paris, France, December 1-2, 1994. Proceedings]. Ann Gastroenterol Hepatol (Paris); 1994 Sep.

14. Consensus conference, editor [ Prevention Screening and Management of the Colonic Cancers. Paris, France, January 29-30, 1998. Proceedings]. Gastroenterol Clin Biol; 1998 Mar.

15. Agence Nationale d'Accréditation et d'Evaluation en Santé. [Consensus conference. Prevention, diagnosis and treatment of colon cancer]. Gastroenterol Clin Biol. 1998;22(2):205-26.

16. Lecomte T, André T, Panis $Y$, Laurent-Puig P, Bibeau F, Taieb J. [colon cancer - National Thesaurus for Digestive cancer ]. The French National Society of Gastroenterology; 2016.

17. Gérard J, André T, Bibeau F, Conroy T, Legoux J, Portier G. [Rectum cancer - National Thesaurus for Digestive Cancer]. The French National Society of Gastroenterology; 2016.

18. Bouche O, Conroy T, Michel P, Penna C, Tournigand C. Metastatic colorectal cancer. Gastroentérologie Clinique et Biologique. 2006;30, Supplement 1:30-42. 
19. van de Velde CJH, Boelens PG, Borras JM, Coebergh J-W, Cervantes A, Blomqvist L, et al. EURECCA colorectal: Multidisciplinary management: European consensus conference colon \& rectum. European Journal of Cancer. 2014;50(1):1.e-.e34.

20. Sobin LH, Gospodarowicz MK, Wittekind C. TNM classification of malignant tumours: John Wiley \& Sons; 2011.

21. Borel C, Lamy S, Compaci G, Récher C, Jeanneau P, Nogaro JC, et al. A longitudinal study of non-medical determinants of adherence to R-CHOP therapy for diffuse large B-cell lymphoma: implication for survival. BMC Cancer. 2015;15:288

22. Pornet C, Delpierre C, Dejardin O, Grosclaude P, Launay L, Guittet L, et al. Construction of an adaptable European transnational ecological deprivation index: the French version. Journal of Epidemiology and Community Health. 2012.

23. Bryere J, Pornet C, Copin N, Launay L, Gusto G, Grosclaude P, et al. Assessment of the ecological bias of seven aggregate social deprivation indices. BMC Public Health. 2017;17(1):86.

24. Goldstein H. Multilevel Statistical Models, 4th Edition: Wiley; 2011.

25. Merlo J, Chaix B, Ohlsson H, Beckman A, Johnell K, Hjerpe P, et al. A brief conceptual tutorial of multilevel analysis in social epidemiology: using measures of clustering in multilevel logistic regression to investigate contextual phenomena. Journal of Epidemiology and Community Health. 2006;60(4):290-7.

26. Daubisse-Marliac L, Biboulet M, Delpierre C, Rivera P, Bauvin E, Grosclaude P. [Completeness and quality of multidisciplinary team meetings: the example of breast cancer in Tarn]. Bull Cancer. 2012;99(9):815-26.

27. Huo Yung Kai S, Delpierre C, Gaudin C, Goddard J, Daubisse-Marliac L, Soulie M, et al. [Completeness and quality of multidisciplinary team meetings: the example of prostate cancer in the Mid-Pyrenees region]. Prog Urol. 2011;21(12):879-86.

28. Dejardin O, Ruault E, Jooste V, Pornet C, Bouvier V, Bouvier A-M, et al. Volume of surgical activity and lymph node evaluation for patients with colorectal cancer in France. Digestive and Liver Disease. 2012;44(3):261-7.

29. Hsieh M-C, Velasco C, Wu X-C, Pareti LA, Andrews PA, Chen VW. Influence of socioeconomic status and hospital type on disparities of lymph node evaluation in colon cancer patients. Cancer. 2012;118(6):1675-83.

30. Leung AM, Scharf AW, Vu HN. Factors Affecting Number of Lymph Nodes Harvested in Colorectal Cancer. Journal of Surgical Research. 2011;168(2):224-30.

31. Morikawa T, Tanaka N, Kuchiba A, et al. Predictors of lymph node count in colorectal cancer resections: Data from us nationwide prospective cohort studies. Archives of Surgery. 2012;147(8):715-23.

32. Edler $D$, Öhrling $K$, Hallström $M$, Karlberg $M$, Ragnhammar $P$. The number of analyzed lymph nodes - a prognostic factor in colorectal cancer. Acta Oncologica. 2007;46(7):975-81.

33. Pappalardo G, Nunziale A. Lymph Node Evaluation as a Predictor of Survival after Resection for Colorectal Cancer. Journal of the American College of Surgeons. 2012;214(1):125.

34. Swanson R, Compton C, Stewart A, Bland K. The Prognosis of T3NO Colon Cancer Is Dependent on the Number of Lymph Nodes Examined. Ann Surg Oncol. 2003;10(1):65-71.

35. Wong SL, Ji H, Hollenbeck BK, Morris AM, Baser O, Birkmeyer JD. HOspital lymph node examination rates and survival after resection for colon cancer. JAMA. 2007;298(18):2149-54.

36. Sobin LH, Greene FL. TNM classification: clarification of number of regional lymph nodes for pNo. Cancer. 2001;92(2):452.

37. Gagliardi AR, Wright FC, Khalifa MA, Smith AJ. Multiple factors influence compliance with colorectal cancer staging recommendations: an exploratory study. BMC Health Serv Res. 2008;8:34.

38. Lepage C, Bouvier A-M, Binquet C, Dancourt V, Coatmeur O, Faivre J. Are the recommendations of the French consensus conference on the management of colon cancer followed up? European Journal of Cancer Prevention. 2006;15(4):295-300.

39. Ganz PA. Does (or should) chronologic age influence the choice of cancer treatment? Oncology (Williston Park, NY). 1992;6(2 Suppl):45-9. 
40. Foster JA, Salinas GD, Mansell D, Williamson JC, Casebeer LL. How Does Older Age Influence Oncologists' Cancer Management? The Oncologist. 2010;15(6):584-92.

41. Ciardiello F, Tejpar S, Normanno N, Mercadante D, Teague T, Wohlschlegel B, et al. Uptake of KRAS mutation testing in patients with metastatic colorectal cancer in Europe, Latin America and Asia. Targ Oncol. 2011;6(3):133-45.

42. Lievre A, Artru P, Guiu M, Laurent-Puig P, Merlin JL, Sabourin JC, et al. The KRAS mutation detection within the initial management of patients with metastatic colorectal cancer: a status report in France in 2011. Eur J Cancer. 2013;49(9):2126-33. 


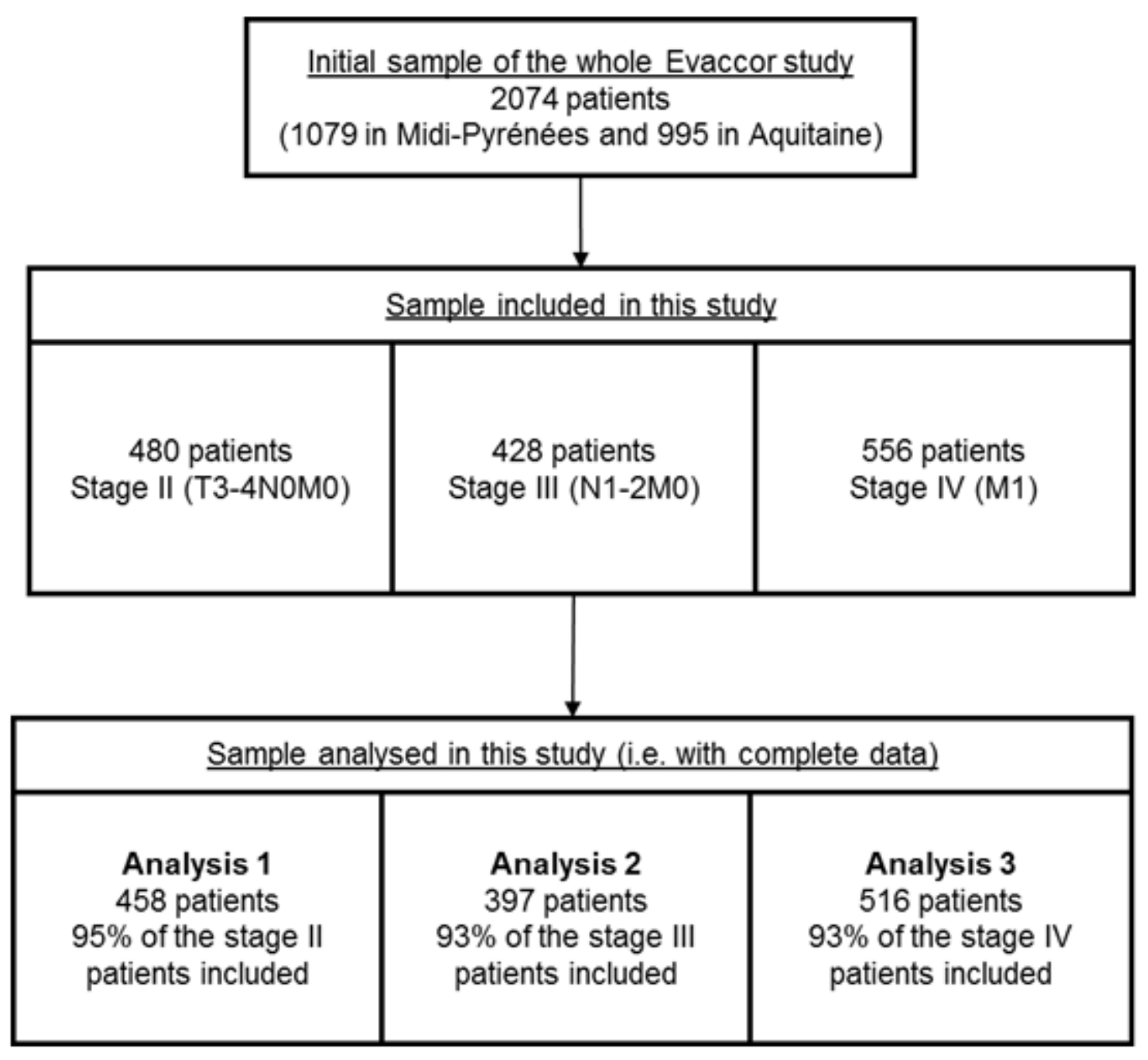

